Workplace ostracism and job performance: Roles of self-efficacy and job level

Dirk De Clercq

Inam Ul Haq

Muhammad Umer Azeem

Paper accepted for Personnel Review 


\title{
Workplace ostracism and job performance: Roles of self-efficacy and job level
}

\begin{abstract}
Purpose-This study investigates how employees' perceptions of workplace ostracism might reduce their job performance, as well as how the negative workplace ostracism-job performance relationship might be buffered by their self-efficacy. It also considers how this buffering role of self-efficacy might vary according to employees' job level.

Design/methodology/approach—Quantitative data came from a survey of employees and their supervisors in Pakistani organizations.

Findings-Workplace ostracism relates negatively to job performance, but this relationship is weaker at higher levels of self-efficacy. The buffering role of self-efficacy is particularly strong among employees at higher job levels.

Practical implications-Organizations that cannot prevent some of their employees from feeling excluded by other members can counter the related threat of underperformance by promoting employees' confidence in their own skills and competencies. This measure is particularly useful among higher-ranking employees.
\end{abstract}

Originality/value - This study provides a more complete understanding of the circumstances in which workplace ostracism is less likely to diminish employees' job performance, by specifying the concurrent influences of workplace ostracism, self-efficacy, and job level.

Keywords-workplace ostracism, job performance, self-efficacy, conservation of resources theory

Paper type-Research paper 


\section{Introduction}

The presence of stressful, adverse workplace conditions is a primary reason employees are unable to complete their job tasks (Abbas et al., 2014; Jamal, 1985; Ng and Feldman, 2012). Understanding employees' ability to meet their organization's performance expectations is an important pursuit, because this ability contributes to positive employee attitudes, including organizational commitment and job satisfaction (MacKenzie et al., 1998), and it diminishes turnover intentions (Zimmermann and Darnold, 2009). Many studies emphasize the importance of positive work features that signal organizational support to drive work outcomes (e.g., Eisenberger et al., 2001; Hussain and Asif, 2012; Khurram, 2009), but a compelling need also exists to understand the "dark side" of organizational life, including employees' exposure to misbehaviours that create stress and hardship as they attempt to undertake their daily job tasks (Baruch and Vardi, 2016; Vardi and Weitz, 2004). Examples of such misbehaviour include dysfunctional organizational politics (Abbas et al., 2014), interpersonal conflicts (Siu et al., 2013), and psychological contract violations (Raja et al., 2011)—factors that speak generally to employees' dissatisfaction with how they are treated by their colleagues or their employer.

Another notable source of organizational misbehaviour is social exclusion or the absence of adequate peer attention, also known as workplace ostracism (Ferris et al., 2008). When they are ostracized, employees feel excluded from social interactions with organizational peers and thereby suffer significant knowledge deficiencies about how their organization operates (Jones et al., 2009). Workplace ostracism may become manifest in different ways, such as receiving "the silent treatment" or not being invited to business meetings or social gatherings (Williams, 2001). Such ostracism can lead to various negative consequences, including poor physiological health, greater emotional exhaustion, and increased turnover intentions (Ferris et al., 2008; Hitlan et al., 
2006; Wu et al., 2012). Yet despite the general sense that workplace ostracism is harmful for employees, previous research offers only equivocal support for its negative effects on employees' ability to meet their expected performance targets. This ambiguity might be due to employees' varied responses to being ostracized, according to their personal characteristics (Liu et al., 2013; Wu et al., 2012), such as the extent to which their self-esteem is contingent on their workplace performance (Ferris et al., 2015). Thus, employees might not always underperform when they are ostracized, and the question of which circumstances tend to lead to negative performance effects remains largely unanswered. Yet this question is critical for organizations, especially complex firms that cannot avoid a situation in which some employees will feel excluded or sense that they have been deprived of critical knowledge needed to complete their job tasks (Fox and Stallworth, 2005; Williams, 2001).

To investigate the possible harmful effects of workplace ostracism on job performancedefined herein as the extent to which employees meet their in-role performance requirementsand how this effect might be contained, the current study draws from conservation of resources (COR) theory (Hobfoll, 1989). According to this theory, the stress associated with workplace adversity depletes employees' energy resources, reducing their propensity to engage in performance-enhancing work behaviours (Ng and Feldman, 2012; Stock, 2015). Such resource losses might occur, for example, if employees feel isolated or lack access to critical organizational knowledge that would enable them to function effectively (Jones et al., 2009). Moreover, COR theory predicts an important buffering role of employees' personal resources, such that these resources help employees cope with work situations that create resource losses (Abbas et al., 2014; Hobfoll, 2001). The current study proposes that employees' self-efficacy represents one such critical personal resource that might buffer the negative relationship between 
workplace ostracism and job performance. Self-efficacy captures employees' beliefs that they have sufficient competencies to complete their job tasks successfully (Bandura, 1997; Gist and Mitchell, 1992; Parker, 1998). Thus, consistent with COR theory, self-efficacy might function as a personal resource that compensates for the resource loss caused by being excluded from social interactions with organizational peers (Hobfoll, 2001).

In sum, in response to calls to devote more attention to the dark side of organizational careers (Baruch and Vardi, 2016; Vardi and Weitz, 2004) and apply contingency approaches to the outcomes of workplace ostracism (Ferris et al., 2015; Liu et al., 2013; Wu et al., 2012), this study addresses the hitherto unexplored question of how employees' limited ability to meet their performance requirements, in the presence of workplace ostracism, might be mitigated by the personal resource of self-efficacy, consistent with the COR theory-based argument that personal resources help people overcome the adversity associated with resource-depleting work conditions (Hobfoll, 2001). Identifying self-efficacy as a potential buffer of the workplace ostracism-job performance relationship also extends previous research that reveals how selfefficacy mitigates and reduces the harmful effects of other workplace stressors, such as unmet job expectations (Maden et al., 2016), emotionally charged social interactions (Heuven et al., 2006), or work-family conflict (Glaser and Hecht, 2013).

Moreover, this study contributes to research on the negative outcomes of organizational misbehaviour and workplace ostracism by testing whether the buffering role of self-efficacy might be particularly salient among people employed in higher job levels. Previous research suggests that the usefulness of personal resources for mitigating the negative effect of workplace adversity cannot be considered in isolation of the preferential knowledge access that employees gain with higher hierarchical positions (Colbert et al., 2005; Hrebiniak, 1974), yet this point has 
not been considered in previous applications of COR theory to the study of workplace stressor outcomes, let alone the performance consequences of workplace ostracism (Ferris et al., 2015). Self-efficacy might mitigate the harmful effect of workplace ostracism on job performance, but the relative importance of this personal resource may be particularly salient when employees' job level provides them with enhanced insights into how they can apply their personal knowledge bases effectively to become immune to the challenge of social exclusion.

Overall, this study seeks to establish a more complete understanding of the circumstances in which the phenomenon of workplace ostracism can diminish employees' job performance. That is, it extends extant literature by specifying the combined influences of workplace ostracism, self-efficacy, and job level in influencing job performance. We propose a critical buffering influence of the personal resource of self-efficacy, which should be particularly salient among employees who occupy higher positions in the organizational hierarchy.

\section{Theoretical Background and Hypotheses}

When employees believe that their surrounding work environment prevents them from fulfilling their job duties and hinders their career prospects, they may become disillusioned about their employment situation and even consider leaving the organization (Chen et al., 2011; Zimmermann and Darnold, 2009). A negative characteristic that marks many work organizations is the sense of ostracism or exclusion that organizational members might feel (Williams, 2001). When employees are ostracized, they cannot enter into social interactions with other organizational members (Ferris et al., 2008; Parker, 1998), and such workplace ostracism may have even more detrimental effects on employees' well-being than direct verbal abuse or outright aggression and bullying, because it undermines the basic need to belong and gain meaning (Williams, 2001; Zadro et al., 2004, 2005). Although ostracism overlaps to some extent with 
other deviant workplace behaviours, it is conceptually distinct and can explain additional variance in employee work outcomes, so it deserves further attention (Liu et al., 2013).

Research into the physical and emotional consequences of workplace ostracism highlights outcomes such as physical pain, aggression, anger, and depression (Leary et al., 2006; MacDonald and Leary, 2005; Smith and Williams, 2004; Stroud et al., 2000). Other studies, focused on the impacts on employee behaviours, reveal that perceptions of being ostracized diminish employees' pro-social behaviours (Twenge et al., 2007) and stimulate aggression, even toward colleagues not directly involved in the ostracism (Twenge et al., 2001). Yet relatively little research considers the impact of workplace ostracism on employees' ability to meet their performance targets, with the notable exception of Ferris and colleagues (2015), who investigate the relationship of workplace ostracism with performance on in-role task behaviours.

Yet the ability to meet pre-set performance standards represents a critical concern of both employees and their organizations (McCarthy et al., 2016; Motowidlo, 2003), so careful consideration of when a workplace stressor such as ostracism is likely to undermine job performance is critical. While a review of previous job performance conceptualizations is beyond the scope of this study_-for detailed discussions, see Campbell et al. (1996), Motowidlo (2003), or Motowidlo et al. (1997) — our focus on the impact of workplace ostracism on employees' aggregate in-role contributions to organizational effectiveness (Williams and Anderson, 1991) is consistent with prior studies of the performance outcomes of specific forms of workplace stress (e.g., Abbas et al., 2014; De Clercq et al., 2017; Naseer et al. 2016). However, research has yet to address the potential influence of the personal resource of selfefficacy on the likelihood that workplace ostracism hinders such performance-enhancing contributions or the role of job level in this process. 
The conceptual framework (Figure 1) addresses these concerns. The baseline relationship illustrates the link between employees' perceptions of workplace ostracism and job performance, moderated by their self-efficacy. Consistent with COR theory, workplace ostracism should diminish job performance, but the effect is mitigated by high self-efficacy. The usefulness of self-efficacy for buffering the workplace ostracism-job performance relationship also should be stronger for employees in higher job levels.

[Insert Figure 1 about here]

\section{Workplace Ostracism and Job Performance}

According to COR theory, the energy depletion that employees experience when they face adverse work situations, such as when they are ostracized, may become so distracting that it diminishes their ability to meet their job requirements (Abbas et al., 2014; Hobfoll, 2001; Ng and Feldman, 2012). Employees tend to feel more energized when undertaking their job tasks if they believe their colleagues are supportive and include them in daily interactions (Quinn et al., 2012; Williams, 2007). This belief is less likely when employees instead have the sense that they are being ignored or excluded by others (Wu et al., 2012). When employees feel stressed by their work situation, they likely allocate their resources toward negative activities, such as worrying and agonizing, instead of productive behaviours that might contribute to the successful execution of their job tasks (Jamal, 1985; McCarthy et al., 2016). If employees sense that they are being ignored and deprived of social support, they also may fear for their personal standing in the organization, and the associated drainage of energy prevents them from devoting sufficient effort to meeting the performance standards set by their organization (Williams, 2001). Workplace ostracism also implies that employees cannot turn to other members to gather relevant knowledge during the execution of their job tasks, so their ability to meet pre-set performance 
standards is thwarted even further (Seibert et al., 2001). The social isolation associated with workplace ostracism thus prevents employees from gaining access to knowledge that they might need to resolve challenges in their daily jobs (Jones et al., 2009).

Because employees may perceive that persistent social exclusion threatens their future success in the organization, workplace ostracism also can lead to self-fulfilling prophecies in peer interactions. For example, if employees believe their colleagues do not take them seriously and exclude them from important conversations, they might retaliate by not freely sharing their own knowledge bases (Gkorezis and Bellou, 2016). This behaviour may produce a negative reinforcement cycle, intensifying employees' social isolation (Liu et al., 2013; Williams, 2001) and undermining their ability to complete their job tasks successfully. Similarly, employees who feel excluded are less likely to contribute to enhance the well-being of other organizational members (Twenge et al., 2007), which hampers their ability to rely on those others' knowledge bases when seeking to meet their own performance targets (Jones et al., 2009). In contrast, when they are included in conversations and events, employees likely have access to relevant peer knowledge, which they can leverage to meet their job obligations, rather than being distracted by negative feelings of isolation from the rest of the organization (Jones et al., 2009).

In addition to reducing their ability, workplace ostracism may also undermine employees' motivation to meet job requirements. According to COR theory, adverse work conditions lead to lower job performance because they motivate employees to conserve their resources (Hobfoll, 2001). If they feel excluded from important organizational knowledge, employees likely feel frustration or even anger (Leary et al., 2006), which threatens their happiness with their job and career situation in general (Ferris et al., 2008). Employees' willingness to allocate significant energy to meet their job requirements thus diminishes when they are overcome by negative 
perceptions of how their colleagues treat them (Abbas et al., 2014). Workplace ostracism also might lead to an escalation of employees' doubts about whether their contributions are appreciated, to the extent that they interpret being ostracized as a signal of a lack of confidence in their helping intentions (Williams, 2001). This misattribution can generate negative feelings about the employer, making employees even less likely to engage in diligent work efforts that could benefit their organization (Wu et al., 2012). That is, employees may interpret their social exclusion as a sign of disrespect, fuelling perceptions that their organization is not interested in their well-being or success (Ferris et al., 2008). Accordingly, employees' job performance may diminish in response to increasing levels of workplace ostracism.

Hypothesis 1. There is a negative relationship between employees' workplace ostracism and job performance.

\section{Moderating Role of Self-Efficacy}

The negative relationship between workplace ostracism and job performance may be moderated by self-efficacy. According to COR theory, the negative effect of resource-draining work conditions on productive employee behaviours diminishes when employees have access to personal resources that compensate for the resource loss (Hobfoll, 2001). Self-efficacy is one such personal resource that enables employees to find effective ways to discover solutions to adverse work situations (Bandura, 1997; Schmitz and Ganesan, 2014). In particular, high levels of self-efficacy are associated with increased effort to understand the origin of the resourcedraining work situations (Abbas et al., 2014; Mastenbroek et al., 2014); the insights developed from such efforts - for example, a better understanding of the reasons organizational members might exhibit ostracism — should mitigate the hardships experienced due to being excluded by others (Hobfoll, 2001; Williams, 2001). Highly efficacious employees who face workplace 
challenges also may invest significant energy to undo the negative consequences, such as by using their personal knowledge to explain to others that ostracism is detrimental for the organization. Less efficacious employees instead might just get stuck in negative thoughts and circular thinking about the situation (van Seggelen-Damen and van Dam, 2016).

In addition, self-efficacy should enhance employees' ability to deal with the deficiencies in organizational knowledge that result from workplace ostracism (Jones et al., 2009), because they have confidence that they can apply relevant personal knowledge to overcome these deficiencies (Wood and Bandura, 1989). This confidence limits the depletion of energy resources that they experience when they are ignored by others and helps avert the threat of reduced job performance (Abbas et al., 2014). Similarly, employees who exhibit higher self-efficacy may identify different pathways that would enable them to complete their job tasks successfully, even if they lack access to relevant organizational knowledge as a result of being ostracized. In particular, efficacious people tend to engage in diverse knowledge processing when they confront adverse work situations (Bandura, 1997; van Seggelen-Damen and van Dam, 2016), which should increase their ability to cope with the situation and maintain adequate job performance. Prior research similarly suggests that employees with high levels of self-efficacy use more divergent and effective coping strategies in the presence of stressful work situations, compared with less efficacious counterparts (Heuven et al., 2006; Lazarus and Folkman, 1984). Employees who have confidence in their personal competencies also tend to be attracted to challenging work situations (Gagne and Deci, 2005) and try to find ways to reach performance targets even in the face of workplace ostracism; dealing with this challenge can add to their feelings of personal accomplishment (Lee and Akhtar, 2007). Thus, self-efficacy is a personal resource that might stimulate not only employees' ability to address the negative consequences 
of workplace ostracism but also a sense of personal joy derived from this process (Bandura, 1997; Ryan and Deci, 2000). In contrast, when employees have low self-efficacy, they derive less joy from working hard and tend to be more passive in their efforts to resolve adverse situations (Gist and Mitchell, 1992; Lee and Akhtar, 2007), which reduces the likelihood that they can meet their job requirements in the presence of workplace ostracism. Overall then, the personal resource of self-efficacy should act as a buffer in the negative relationship between workplace ostracism and job performance.

Hypothesis 2. The negative relationship between employees' workplace ostracism and job performance is moderated by their self-efficacy, such that the relationship is weaker at higher levels of self-efficacy.

\section{Effect of Job Level on the Buffering Role of Self-Efficacy}

The buffering role of self-efficacy in turn may be invigorated by employees' job level, which suggests a three-way interaction effect among workplace ostracism, self-efficacy, and job level. That is, as predicted in $\mathrm{H} 2$, at higher levels of self-efficacy, the likelihood that workplace ostracism diminishes job performance decreases, because highly efficacious employees have greater abilities and motivation to deal with the challenge of being excluded by other members, so the likelihood that workplace ostracism undermines their ability to meet job requirements is lower (Bandura, 1997; Lee and Akhtar, 2007; Mastenbroek et al., 2014). We expect that this personal resource may be particularly useful for overcoming workplace ostracism among employees who rank higher in the organizational hierarchy. These employees have a more comprehensive overview of where to find relevant knowledge for their effective organizational functioning (Colbert et al., 2005; Hrebiniak, 1974), which should provide a deeper understanding of which aspects of their personal skills are best suited to overcome the knowledge deficiencies they suffer due to their social exclusion. That is, higher positions in the organizational hierarchy 
provide employees with a better understanding of how to apply their own competencies and skills efficiently to organizational-level decisions that affect their job performance (Choudhury and Jones, 2010). In turn, they likely can cope better with the challenges that arise when colleagues deprive them of access to critical organizational knowledge (Jones et al., 2009). This understanding then increases their ability to maintain adequate job performance in the presence of high workplace ostracism.

High self-efficacy can have a dark side too, to the extent that it invokes overconfidence (Vancouver et al., 2002) or creates unrealistic expectations about how well employees can leverage their personal knowledge to resolve unfavourable situations, such as workplace ostracism. This challenge should be less prominent when employees occupy higher organizational positions though, because the preferential access to organizational knowledge that they gain through their organizational rank may enable them to make more accurate assessments of the motivations that underlie others' ostracism and develop a more realistic view of how their own knowledge bases can help overcome those motivations (Colbert et al., 2005; Mintzberg, 1973). Thus, highly efficacious employees in higher job levels may be less likely to suffer from overconfidence when seeking ways to cope with the threat of workplace ostracism. Conversely, overconfidence accompanying extreme levels of self-efficacy may be a greater challenge for employees who operate at lower levels of the organization, because they have a less comprehensive understanding of which skills are needed to counter workplace ostracism (Choudhury and Jones, 2010; Hrebiniak, 1974). For example, a more limited view of how the organization functions - such as a lack of understanding of the underlying reasons for an organizational culture that is marked by social exclusion-may lead them to believe falsely that their personal skills are sufficient to resolve knowledge deficiencies due to social exclusion. In 
turn, the buffering effect of self-efficacy should be stronger for employees who operate at higher levels of the organization.

Hypothesis 3. The buffering effect of self-efficacy on the negative relationship between employees' workplace ostracism and job performance is moderated by their job level, such that this buffering effect is stronger for employees at higher job levels.

\section{Research Method}

\section{Sample and Data Collection}

The data for this study came from surveys of Pakistani employees, who work in multiple sectors, such as banking, telecommunication, and textiles. One of the authors leveraged personal and professional contacts to gain access to 22 organizations. English is the official language of correspondence for professional organizations in Pakistan, as well as the official language of instruction in schools, so the survey questions were provided in English.

The data collection process involved three separate paper-and-pencil surveys and included a time lag of three weeks between the measurement of the independent variable (workplace ostracism) and dependent variable (job performance). The first survey asked employees about their perceptions of workplace ostracism, their job level, and their demographic characteristics. The second survey, conducted about three weeks later, assessed employees' selfefficacy levels. The third survey was conducted at the same time as the second one, but the respondents differed, such that it targeted supervisors, asking them to rate the extent to which employees were able to meet their performance requirements. The three-week time lag between surveys was long enough to minimize the threat of reverse causality—namely, that some employees might be ostracized by colleagues because they appear weak and cannot meet their performance targets — but sufficiently short to reduce the likelihood that significant, 
performance-changing organizational events might occur between the assessments of workplace ostracism and job performance.

Cover letters included with all three surveys explained the purpose of the study and the complete confidentiality of all responses (i.e., accessible only by the research team, no information at the individual level ever made public, and only aggregate data accessible to people beyond the research team). Moreover, the surveys highlighted that there were no correct or incorrect answers and requested that the respondents answer the questions as honestly as possible, to help reduce concerns about social desirability or acquiescence biases (Spector, 2006). Of the 500 surveys distributed initially, 360 completed surveys were returned, for a response rate of $72 \%$. The second survey, administered three weeks later to the 360 respondents from the first round, produced 278 completed surveys, for a response rate of $78 \%$. Finally, the supervisors of these respondents generated 258 completed sets of surveys. Among the employee respondents, $25 \%$ were women, $84 \%$ were younger than 40 years, and $46 \%$ held managerial responsibilities.

\section{Measures}

Job performance. The measure of job performance used seven items from prior research pertaining to supervisor-rated job performance, with five-point Likert scales (Williams and Anderson, 1991). For example, two measurement items were, "This employee adequately completes assigned duties" and "This employee fulfills responsibilities specified in job descriptions" (Cronbach's alpha $=.94)$.

Workplace ostracism. Ten items served to measure workplace ostracism (seven-point Likert scale), as developed by Ferris and colleagues (2008) and applied in previous studies (e.g., 
Ferris et al., 2015; Wu et al., 2012), including for example, "Others refuse to talk to me at work" and "Others avoid me at work" (Cronbach's alpha $=.87)$.

Self-efficacy. To capture employees' self-efficacy, respondents answered six items from previous studies (Luthans et al., 2007; Parker, 1998), using a six-point Likert scale. Two example statements were "I feel confident analyzing a long-term problem to find a solution" and "I feel confident presenting information to a group of colleagues" (Cronbach's alpha $=.79$ ).

Job level. To measure employees' job level, the first survey asked respondents "whether they occupied a staff position or managerial position", preceded by a statement that clarified that a staff function implied the respondent had no supervisory responsibilities, whereas a managerial position included such responsibilities. By providing these specifications, the survey method ensured that the respondents understood and selected the correct category, namely, the one that best matched their situation. The staff position was used as the base category for the regression analysis.

Control variables. Similar to previous studies of job performance (e.g., Ng and Feldman, 2009; Watt and Hargis, 2010), we controlled for employees' gender ( $0=$ male; $1=$ female $)$, age $(1=20-40$ years, $2=41-60$ years, $3=$ older than 60 years $)$, and education $(1=$ high school; $2=$ undergraduate; 3 = masters; $4=$ doctorate). These controls reflect the possibilities that women might be more diligent that men in their job efforts, or that the knowledge gains that come with age and more education might increase employees' ability to meet organizational performance standards. ${ }^{1}$

Confirmatory factor analysis applied to a three-factor measurement model supported the assessments of the convergent and discriminant validity of the three focal constructs (Anderson

\footnotetext{
${ }^{1}$ Following Becker's (2005) recommendations for dealing with control variables that are not significant in regression models, as was the case here (Table 2), a robustness check involved rerunning the regression models without the control variables. The hypothesis results remained consistent.
} 
and Gerbing, 1988). Although absolute fit indices such as the goodness-of-fit index (GFI) and adjusted goodness-fit-index (AFGI) often serve to assess measurement model fit, they have been criticized; Hu and Bentler (1998) recommend complementing these indices with incremental or comparative fit indices (e.g., comparative fit index [CFI], normed fit index [NFI], Tucker-Lewis index [TLI]) or residual fit indices (e.g., standardized root mean residual [SRMR], root mean square error of approximation [RMSEA]) (see also Bentler, 1995; Joreskog and Sorbom, 1986). Monte Carlo studies reveal that such indices offer more robust measures than their absolute fit counterparts (e.g., Fan et al., 1999; Hu and Bentler, 1998; Jackson, 2007; Marsh et al., 1996). Our measurement model yields an adequate fit according to all these fit indices $\left(\chi_{(219)}^{2}=310.91\right.$, $\chi^{2} / \mathrm{df}=1.42, \mathrm{GFI}=.91, \mathrm{AGFI}=.89 ; \mathrm{CFI}=.97, \mathrm{NFI}=.91, \mathrm{TLI}=.97, \mathrm{SRMR}=.05, \mathrm{RMSEA}=$ $.04){ }^{2}$ Table 1 provides the factor loadings for each construct, providing evidence of their convergent validity, in that the factor loadings for each item are significant $(\mathrm{t}>2.0, p<.05)$. In support of discriminant validity, the comparison of the constrained models, in which the correlations were set to 1 , with the unconstrained models, in which the correlations could vary freely, indicated significant differences for all three pairs of constructs $\left(\Delta \chi_{(1)}^{2}>3.84\right)$ (Anderson and Gerbing, 1988).

[Insert Table 1about here]

\section{Results}

Table 2 contains the zero-order correlations and descriptive statistics, and Table 3 provides the regression results using SPSS version 23. Model 1 included the control variables; Model 2 added workplace ostracism, self-efficacy, and job level; Model 3 added the workplace

\footnotetext{
${ }^{2}$ In addition to this recommended approach for assessing the fit of a measurement model that includes all constructs together - thereby accounting for their mutual dependencies or correlations and providing a comprehensive assessment of construct validity (Anderson and Gerbing, 1988) - a supplementary assessment considered the fit indices for the three focal constructs separately. The values were consistent with those for the comprehensive measurement model.
} 
ostracism $\times$ self-efficacy interaction term; and Model 4 added the three-way interaction term of workplace ostracism $\times$ self-efficacy $\times$ job level, together with the three constitutive two-way interactions, as recommended by Aiken and West (1991). For both the two- and three-way interaction terms, the product terms were mean centred (Aiken and West, 1991).

[Insert Tables 2 and 3 about here]

In support of the baseline prediction that being excluded by other members reduces the likelihood that employees meet their performance targets, Model 2 revealed that workplace ostracism related negatively to job performance ( $\beta=-.334, p<.001)$, in strong support of $\mathrm{H} 1$. Although not part of the theoretical foundation, the results in Model 2 also indicated a direct positive relationship between self-efficacy and job performance $(\beta=.378, p<.001)$ but no significant relationship between job level and job performance $(\beta=.025, n s)$.

Model 3 supported the hypothesized buffering effect of self-efficacy $(\beta=.248, p<.001)$ on the negative workplace ostracism-job performance relationship. The negative relationship between workplace ostracism and job performance was less pronounced when employees had greater confidence in their abilities and competencies (H2). To clarify the nature of this interaction, Figure 2 plots the effects of workplace ostracism on job performance at high and low levels of self-efficacy, combined with a simple slope analysis (Aiken and West, 1991). The results of the simple slope analysis indicated that the relationship between workplace ostracism and job performance was significant when self-efficacy was low $(\beta=-.578, p<.001)$ but became insignificant when it was high $(\beta=-.082, n s)$, in further support of $\mathrm{H} 2$.

[Insert Figure 2 about here]

Finally, the results supported the three-way interaction effect among workplace ostracism, self-efficacy, and job level predicted in $\mathrm{H} 3$ (Model $4, \beta=.576, p<.001$ ). The positive 
moderating (buffering) effect of self-efficacy on the workplace ostracism-job performance relationship was stronger at higher job levels. To clarify this interaction, Figure 3 contains the plots of the moderating effect of self-efficacy on the workplace ostracism-job performance link at high (Panel A) versus low (Panel B) job levels. At low levels, the two lines are closer to being parallel, whereas at high levels (Panel A), self-efficacy exerts a strong buffering effect on the relationship between workplace ostracism and job performance. As Dawson and Richter (2006) suggest, a further assessment considered the significance of the slope differences. According to Figure 3, Panel B, the slope difference between the two conditions of self-efficacy was not significant $(\mathrm{t}=-1.146, n s)$, but the slope difference in Panel A was strongly significant $(\mathrm{t}=$ $4.530, p<.001)$, in further support of $\mathrm{H} 3$.

[Insert Figures 3A-B about here]

\section{Discussion}

\section{General Findings}

The demonstration of a direct negative relationship between workplace ostracism and job performance extends findings in previous research about how being ostracized diminishes positive work behaviours, such as pro-social behaviour (Twenge et al., 2007), and fuels negative ones, such as self-serving behaviour (Gkorezis and Bellou, 2016). The mechanisms that underpin this relationship may stem from both capability and motivation. First, beliefs about being excluded from social interactions with other members are stressful and deplete employees' energy resources, which prevent them from devoting sufficient effort to completing their job tasks (Ng and Feldman, 2012). These beliefs also may initiate negative reinforcement cycles, in which employees refuse to share relevant knowledge with others and ultimately become even more isolated (Gkorezis and Bellou, 2016; Jones et al., 2009; Williams, 2001). Second, 
workplace ostracism generates feelings of frustration or anger in employees (Hitlan et al., 2006; Leary et al., 2006; Wu et al., 2012) and fuels a belief that the organization is not interested in their personal development or success. This belief may undermine employees' willingness to carry out job activities from which their organization otherwise could benefit.

The translation of workplace ostracism into reduced job performance also depends on employees' self-efficacy though. The resource depletion effect of adverse work situations may be subdued to the extent that people can draw from relevant personal resources (Hobfoll, 2001). Thus, the likelihood that employees fail to meet their performance targets as a result of being ostracized diminishes when employees feel more confident about their ability to complete their job tasks. Finding ways to meet performance standards in the presence of social exclusion requires the confidence that one can find creative solutions to the knowledge deficiencies that come with isolation (Jones et al., 2009), such as by leveraging personal skills and competencies (Bandura, 1997). Employees with high self-efficacy levels also derive personal joy from seeking and finding solutions to adverse work situations and are strongly motivated to ensure adequate job performance, regardless of being ostracized (Bandura, 1997; Ryan and Deci, 2000). This motivation then reduces the stress due to perceptions of being ignored or excluded (Wu et al., 2012) and the likelihood that employees fail to meet their performance targets in such situations. Conversely, employees who cannot draw from the personal resource of self-efficacy are less able or motivated to find effective ways to cope with workplace ostracism, so negative outcomes, in the form of reduced job performance, are more likely to materialize (Hobfoll, 2001).

Finally, the usefulness of self-efficacy for countering the harmful effect of workplace ostracism is particularly strong among employees who operate at higher job levels (Figure 3, Panel A) but less useful at lower job levels (Figure 3, Panel B). On the one hand, at higher job 
levels, employees have more oversight and direct influence over how to apply their personal knowledge bases to overcome the knowledge deficiencies that result from being excluded from social interactions (Hrebeniak, 1974). Their higher job level also diminishes the danger that selfefficacious employees become overconfident in their ability to undo the harm caused by workplace ostracism, because they can leverage these skills with greater efficiency (Choudhury and Jones, 2010). For example, with their preferential access to organizational knowledge about why others might engage in ostracism, as afforded by their higher organizational position, higher-ranking employees have a more realistic understanding of how they can leverage their own knowledge bases to counter these motives. On the other hand, employees at lower job levels are relatively poorly positioned to leverage their personal skills to overcome the knowledge deficiencies that result from being ostracized.

Summary of Theoretical Contributions

Overall, this study's findings contribute to extant research by elaborating on how selfefficacy influences the negative relationship between workplace ostracism and job performance. The scope of the tested model is narrow, yet the goal of this study is to achieve depth, rather than breadth, by dedicating significant theoretical attention to how the resource depletion that comes with disrespectful organizational treatments might be contained by the important personal resource of self-efficacy (Bandura, 1997; Gist and Mitchell, 1992). Consistent with COR theory (Hobfoll, 2001), employees' self-efficacy mitigates the likelihood that they fail to meet their performance targets in response to increasing levels of workplace ostracism, a positive role that has not been considered in previous studies of this personal resource.

In addition, extant scholarship has pointed out that organizational rank can give employees preferential access to organizational knowledge (Colbert et al., 2005; Hrebiniak, 
1974), but it has not investigated its influence on the relative importance of a knowledge-driven resource, such as self-efficacy, for diminishing the hardship that comes with social exclusion. This study reveals that the potency with which self-efficacy diminishes the negative influence of workplace ostracism on job performance is particularly salient among employees who occupy higher positions in the organizational hierarchy.

\section{Limitations and Future Research}

This study has some shortcomings that suggest further research opportunities. First, we did not directly measure the causal mechanisms that underlie the hypothesized relationships. Being ostracized depletes employees' energy resources, which may reduce their ability and motivation to dedicate significant efforts to meeting their job requirements. Similarly, high levels of self-efficacy likely increase people's ability to deal with the hardships that come from workplace ostracism, as well as the attractiveness of meeting performance standards in this situation. Additional research might measure these underlying mechanisms directly and investigate, for example, whether ability- or motivation-based mechanisms are more prevalent. In a related vein, the intermediate time lag of three weeks between the assessments of workplace ostracism and job performance was designed to reduce the likelihood of reverse causality but still avoid the possibility that significant organizational events might occur during the course of the study. Future studies might use longer time frames to determine if the performance effects of covert forms of social exclusion might become manifest only after a more extended period. To ensure causality, researchers could undertake laboratory or field experiments that include treatment and control groups. The current study's focus on in-role job performance also could be complemented with alternative performance measures, such as the extent to which employees 
engage in extra-role citizenship behaviours directed toward other members or the organization in general (Motowidlo, 2000; Podsakoff et al., 1997).

Second, the parsimonious conceptual model sought to provide a detailed understanding of the role of one specific, important personal resource as a contingency factor (Gist and Mitchell, 1992); continued research could consider other potential buffers of the negative relationship between workplace ostracism and job performance. Other personal resources that might inform the translation of workplace ostracism into different performance outcomes include employees' passion for work (Baum and Locke, 2004) or learning orientation (Hirst et al., 2009). For example, employees who are keen to learn and update their skill sets may regard the challenge of meeting performance standards in the presence of workplace ostracism as a learning opportunity, such that they undertake significant efforts to understand why other members exclude them from their conversations, then develop strategies to address or undo those motivations.

Third, the sample included different organizations that operate in different industries, but it did not address the influence of potentially relevant organizational or industry-level factors. Further studies could explore, for example, how the relationship between workplace ostracism and job performance, and the related roles of self-efficacy and job level, depend on company size. The impersonal nature and complexity of larger organizations might make the experience of workplace ostracism particularly stressful, so the positive roles of self-efficacy and job level could be even more salient. Alternatively, employees who work in smaller organizations might have stronger expectations of being included in social interactions, such that the absence of adequate attention or social support might appear particularly offensive. Another potentially relevant factor is the level of competitive rivalry in the external market. If external pressures on organizational members is high, due to such rivalry, employees might be more willing to accept 
the inevitability of adverse workplace conditions (Lahiri et al., 2008), which could mitigate some of the harmful effects of workplace ostracism on job performance.

Fourth, this study centres on a sample of Pakistan-based organizations, so cultural factors might be relevant. The theoretical arguments are not country-specific, yet Pakistani culture is generally risk averse (Hofstede, 2001); employees in this country might be particularly sensitive to work circumstances that create uncertainty in their organizational functioning. Therefore, the relative importance of self-efficacy for buffering the negative relationship between workplace ostracism and job performance may be stronger than it would be in more risk-prone countries. Cross-country studies could provide deeper insights into the relative usefulness of self-efficacy for preventing stressful work conditions, such as workplace ostracism, from transforming into lower job performance, across different cultural contexts.

\section{Managerial Implications}

This investigation of the contingent nature of the relationship between workplace ostracism and job performance also has practical relevance. The belief that other organizational members ignore or exclude them from social interactions can be a significant source of frustration for employees, and organizations should seek to diminish its occurrence. In this regard, some employees may be hesitant to admit that they feel insulated or ignored, to avoid perceptions that they are weak or complain too much (Williams, 2001). Organizations thus must be proactive in gathering input from employees about the presence of workplace ostracism and identifying reasons for it (e.g., incompatible personalities, discrepant work goals, political manoeuvres). They also could create specific guidelines for when and how organizational members should involve colleagues in social interactions and decision-making processes, depending on their respective expertise and competencies. For example, training could focus on 
how incumbent employees should interact with newcomers and facilitate their socialization through mentoring activities (Thomas and Lankau, 2009).

From a human resource perspective, the study's findings indicate that organizations should focus not only on stimulating positive workplace features that contribute to career success but also on avoiding negative features that reflect the "dark side" of career experiences (Baruch and Vardi, 2016; Vardi and Weitz, 2004). Managers can invest resources in educating employees about why and how to avoid organizational misbehaviours that exclude other members (Ackroyd and Thompson, 1999). Such training might seek to increase awareness of the negative consequences of workplace ostracism for individual employees and the organization in general, such that it can cause destructive retaliation in the form of more aggressive behaviour or less prosocial behaviour (Twenge et al., 2001, 2007). Educational efforts to prevent workplace ostracism could span dedicated training programs that take place outside the workplace, structured on-thejob training efforts, and informal learning, all of which are important sources of employee development (Enos et al., 2003; Jacobs, 2003). Together, these measures can benefit the entire organization to the extent that managers succeed in creating an organizational culture that makes the recognition and prevention of workplace ostracism a critical concern.

Yet human resource managers also should acknowledge that some level of workplace ostracism may be inevitable. Organizations marked by a culture of strong internal resource competition, for example, probably cannot eliminate social exclusion behaviours completely within their ranks (De Clercq et al., 2013). The current study indicates that employees who feel more confident about their personal competencies and skills are better prepared to cope with such workplace ostracism. Employees' self-efficacy represents an important personal resource that organizations can leverage to mitigate stress due to social exclusion or knowledge 
deprivation, by helping employees find adequate solutions to knowledge deficiencies in the presence of ostracism, as well as personal joy from such efforts (Bandura, 1997).

This positive role of self-efficacy has important implications for organizational recruitment. Finding employees with a healthy level of confidence in their own capabilities can enable organizations to maintain adequate performance levels, even in the presence of workplace ostracism. Human resource managers also can benefit from predicting and assessing the intrinsic motivation that employees derive from applying their personal expertise to their job tasks in the presence of a challenging workplace condition such as ostracism (Ryan and Deci, 2000). Thus, the recruitment and retention of self-efficacious employees has strong value for organizations that cannot entirely avoid situations in which some employees are victims of social exclusion and deprived of the knowledge they need to fulfil their job duties.

In addition to benefiting from recruiting employees who are self-efficacious already, organizations can encourage this personal characteristic among their work force (Luthans, 2002; Luthans et al., 2010). To stimulate employees' self-efficacy, organizations could explain, for example, which skills are most needed to cope with adverse peer relationships that deprive employees of knowledge. They also might showcase role models who have been effective in fulfilling their job duties, even with limited access to peer knowledge due to social exclusion dynamics. Employees could grow more confident in their ability to deal with workplace challenges to the extent that they are stimulated to experiment with new ideas to solve issues at work (Scott and Bruce, 1994). Another option would be to design appropriate reward systems; self-efficacious employees might be more motivated to apply their personal expertise to finding adequate solutions to social exclusion situations when they receive formal recognition for these efforts, which ultimately benefits the entire organization (Jacobsen and Bogh Andersen, 2017). 
Finally, the relative value of self-efficacy for reducing the harm caused by workplace ostracism is greatest when employees have a clearer sense, based on their organizational rank, of how and when to apply their personal skills. Measures to enhance self-efficacy in response to workplace ostracism thus should be particularly useful for employees who operate at higher levels of the organizational hierarchy, because their preferential insights into how their organization functions enable them to apply their competencies more effectively toward mitigating the stress due to workplace ostracism. At the same time, employees at lower levels of the organization likely need extra support to leverage their personal skills in ways that make them resilient to the hardships of workplace ostracism. These employees might be most vulnerable to the performance threats of workplace ostracism, and they deserve devoted attention from human resource managers to help overcome these challenges.

\section{Conclusion}

This study unpacks the relationship between employees' exposure to workplace ostracism and job performance by considering the roles of self-efficacy and job levels, with a particular focus on the circumstances in which employees' exposure to workplace ostracism is less likely to reduce their ability to meet performance requirements. The likelihood that being ostracized is associated with lower job performance diminishes to the extent that employees are more confident in their personal abilities. The personal resource of self-efficacy also is particularly potent among employees at higher job levels.

In turn, this study provides critical insights into when employees' exposure to organizational misbehaviour, in the form of social exclusion, is more or less likely to undermine their performance. The sense that they are ignored or excluded by others deprives employees of access to critical organizational knowledge, which hampers their ability to succeed. However, 
access to relevant personal knowledge, facilitated through self-confidence in their own capabilities and organizational rank, is instrumental for meeting job requirements despite experiences of workplace ostracism. This study then might function as a stepping stone for further investigations of how organizations can mitigate the risk that social exclusion within their ranks will escalate into poorer performance outcomes. 


\section{References}

Abbas, M., Raja, U., Darr, W., and Bouckenooghe, D. (2014), "Combined effects of perceived politics and psychological capital on job satisfaction, turnover intentions, and performance", Journal of Management, Vol. 40, pp. 1813-1830.

Ackroyd, S. and Thompson, P. (1999), Organizational Misbehaviour, Sage, London.

Aiken, L.S. and West, S.G. (1991) Multiple Regression: Testing and Interpreting Interactions, Sage, Newbury Park, CA.

Anderson, J.C. and Gerbing, D.W. (1988), "Structural equation modeling in practice: A review and recommended two-step approach", Psychology Bulletin, Vol. 1033, pp. 411-423.

Bandura, A. (1997). Self-Efficacy: The Exercise of Control, Freeman, New York, NY.

Baruch, Y. and Vardi, Y. (2016), "A fresh look at the dark side of contemporary careers: Toward a realistic discourse", British Journal of Management, Vol. 27, pp. 355-372.

Baum, J.R. and Locke, E.A. (2004), “The relationship of entrepreneurial traits, skill, and motivation to subsequent venture growth", Journal of Applied Psychology, Vol. 89, pp. 587598.

Becker, T.E. (2005), "Potential problems in the statistical control of variables in organizational research: A qualitative analysis with recommendations", Organizational Research Methods, Vol. 8, pp. $274-289$.

Bentler, P.M. (1995), EQS Structural Equations Program Manual, Multivariate Software, Encino, CA.

Campbell, J.P., Gasser, M.B., and Oswald, F.L. (1996), "The substantive nature of job performance variability”, In K.R. Murphy, (Ed.), Individual Differences and Behavior in Organizations, Jossey-Bass, San Francisco, pp. 258-299.

Chen, M.-F., Lin, C.-P., and Lien, G.-Y. (2011), "Modelling job stress as a mediating role in predicting turnover intention", Service Industries Journal, Vol. 31, pp. 1327-1345.

Choudhury, A. and Jones, J. (2010), "Effect of job level on the performance of human capital attainment: An exploratory analysis", Academy of Strategic Management Journal, Vol. 9, pp. 89-103.

Colbert, A.E., Rynes, S.L., and Brown, K.G. (2005), "Who believes us? Understanding managers' agreement with human resource research findings?", Journal of Applied Behavioural Science, Vol. 41, pp. 304-325.

Dawson, J.F. and Richter, A.W. (2006), "Probing three-way interactions in moderated multiple regression: Development and application of a slope difference test", Journal of Applied Psychology, Vol. 91, pp. 917-926.

De Clercq, D., Haq, I.U., and Azeem, M.U. (2017), "Perceived threats of terrorism and job performance: The roles of job-related anxiety and religiousness", Journal of Business Research, doi.org/10.1016/j.jbusres.2017.04.013.

De Clercq, D., Thongpapanl, N. and Dimov, D. (2013), "Shedding new light on the relationship between contextual ambidexterity and firm performance: An investigation of internal contingencies", Technovation, Vol. 33, No. 4-5, pp. 119-132.

Eisenberger, R., Armeli, S., Rexwinkel, B., Lynch, P. D., and Rhoades, L. (2001), "Reciprocation of perceived organizational support", Journal of Applied Psychology, Vol. 86, No. 1, pp. 42-51. 
Enos, M.D., Kehrhahn, M.T., and Bell, A. (2003), "Informal learning and the transfer of learning: How managers develop proficiency”, Human Resource Development Quarterly, Vol. 14, pp. 368-387.

Fan, X., Thompson, B., and Wang, L. (1999), "The effects of sample size, estimation methods, and model specification on SEM fit indices", Structural Equation Modeling: A Multidisciplinary Journal, Vol. 6, pp. 56-83.

Ferris, D.L., Brown, D.J., Berry, J.W., and Lian, H. (2008), "The development and validation of the workplace ostracism scale", Journal of Applied Psychology, Vol. 93, pp. 1348-1366.

Ferris, D.L., Lian, H., Brown, D. J., and Morrison, R. (2015), “Ostracism, self-esteem, and job performance: When do we self-verify and when do we self-enhance?", Academy of Management Journal, Vol. 58, pp. 279-297.

Fox, S. and Stallworth, L.E. (2005), "Racial/ethnic bullying: Exploring links between bullying and racism in the US workplace", Journal of Vocational Behavior, Vol. 66, pp. 438-456.

Gagne, M. and Deci, E. L. (2005), "Self-determination theory and work motivation", Journal of Organizational Behavior, Vol. 26, pp. 331-362.

Gist, M.E. and Mitchell, T.R. (1992), "Self-efficacy: A theoretical analysis of its determinants and malleability", Academy of Management Review, Vol. 17, pp. 183-211.

Gkorezis, P. and Bellou, V. (2016), "The relationship between workplace ostracism and information exchange; The mediating role of self-serving behavior", Management Decision, Vol. 54, pp. 700-713.

Glaser, W. and Hecht, T.D. (2013), "Work-family conflicts, threat-appraisal, self-efficacy and emotional exhaustion”, Journal of Managerial Psychology, Vol. 28, pp. 164-182.

Heuven, E., Bakker, A.B., Schaufeli, W.B., and Huisman, N. (2006), "The role of self-efficacy in performing emotion work", Journal of Vocational Behavior, Vol. 69, pp. 222-235.

Hirst, G., Van Knippenberg D., and Zhou, J. (2009), "A cross-level perspective on employee creativity: Goal orientation, team learning behavior, and individual creativity", Academy of Management Journal, Vol. 52, pp. 280-293.

Hitlan, R.T., Cliffton, R.J., and DeSoto, M.C. (2006), "Perceived exclusion in the workplace: The moderating effects of gender on work-related attitudes and psychological health", North American Journal of Psychology, 8, Vol. 21, pp. 7-236.

Hobfoll, S.E. (1989), "Conservation of resources. A new attempt at conceptualizing stress", American Psychologist, Vol. 44, pp. 513-524.

Hobfoll, S.E. (2001), "The influence of culture, community, and the nested-self in the stress process: Advancing conservation of resource theory", Applied Psychology: An International Review, Vol. 50, pp. 337-369.

Hofstede, G. (2001), Culture's Consequences: Comparing Values, Behaviors, Institutions and Organizations across Nations (2d ed.), Sage, Thousand Oaks, CA.

Hrebiniak, L.G. (1974), "Effects of job level and participation on employee attitudes and perceptions of influence", Academy of Management Journal, Vol. 17, pp. 649-662.

Hu, L.T. and Bentler, P.M. (1998), "Fit indices in covariance structure modeling: Sensitivity to underparameterized model misspecification", Psychological Methods, Vol. 3, pp. 424-453.

Hussain, T. and Asif, S. (2012), "Is employees' turnover intention driven by organizational commitment and perceived organizational support?", Journal of Quality and Technology Management, Vol. 8, pp. 1-10.

Jackson, D.L. (2007), "The effect of the number of observations per parameter in misspecified confirmatory factor analytic models", Structural Equation Modeling, Vol. 14, pp. 48-76. 
Jacobs, R.L. (2003). Structured On-the-Job Training: Unleashing Employee Expertise in the Workplace, Berrett-Koehler, San Francisco, CA.

Jacobsen, C.B. and Bogh Andersen, L. (2017), "Leading public service organizations: how to obtain high employee self-efficacy and organizational performance", Public Management Review, Vol. 19, pp. 253-273.

Jamal, M. (1985), "Relationship of job stress to job performance: A study of managers and bluecollar workers", Human Relations, Vol. 38, pp. 409-424.

Jones, E.E., Carter-Sowell, A.R., Kelly, J.R., and Williams, K.D. (2009), “'I'm out of the loop': Ostracism through information exclusion”, Group Processes and Intergroup Relations, Vol. 12, pp. 157-174.

Joreskog, K.G. and Sorbom, D. (1986), LISREL VI: Analysis of Linear Structural Relationships by Maximum Likelihood and Least Squares Methods, Scientific Software, Mooresville, IN.

Khurram, S. (2009), "Perceived organizational support, antecedents and consequences proposing and testing a model in a public sector university of Pakistan", South Asian Journal of Management, Vol. 16, pp. 7-26.

Lahiri, S., L. Pérez-Nordtvedt, and R.W. Renn (2008), "Will the new competitive landscape cause your firm's decline? It depends on your mindset”, Business Horizons, Vol. 51, No. 4, pp. 311-320.

Lazarus, R.S. and Folkman, S. (1984), Stress, Appraisal, and Coping, Springer, New York.

Leary, M.R., Twenge, J.M., and Quinlivan, E. (2006), "Interpersonal rejection as a determinant of anger and aggression", Personality and Social Psychology Review, Vol. 10, pp. 111-132.

Lee, J.S.Y. and Akhtar, S. (2007), "Job burnout among nurses in Hong Kong: Implications for human resource practices and interventions", Asia Pacific Journal of Human Resources, Vol. 45, pp. 63-84.

Liu, J., Kwan, H.K., Lee, C., and Hui, C. (2013), "Work-to-family spillover effects of workplace ostracism: The role of work-home segmentation preferences", Human Resource Management, Vol. 52, pp. 75-94.

Luthans F. (2002), "Positive organizational behavior: Developing and managing psychological strengths", Academy of Management Executive, Vol. 16, pp. 57-72.

Luthans, F., Avey, J.B., Avolio, B.J., and Peterson, S. (2010), "The development and resulting performance impact of positive psychological capital", Human Resource Development Quarterly, Vol. 21, pp. 41-66.

Luthans, F., Avolio, B.J., Avey, J.B., and Norman, S.M. (2007), "Positive psychological capital: Measurement and relationship with performance and satisfaction", Personnel Psychology, Vol. 60, pp. 541-572.

MacDonald, G. and Leary, M. R. (2005), "Why does social exclusion hurt? The relationship between social and physical pain”, Psychological Bulletin, Vol. 131, pp. 202-223.

MacKenzie, S.B., Podsakoff, P.M., and Ahearne, M. (1998), "Some possible antecedents and consequences of in-role and extra-role salesperson performance", Journal of Marketing, Vol. 62, pp. 87-98.

Maden, C., Ozcelik, H., and Karacay, G. (2016), "Exploring employees' responses to unmet job expectations; The moderating role of future job expectations and efficacy beliefs", Personnel Review, Vol. 45, pp. 4-28.

Marsh, H.W., Balla, J.R., and Hau, K.T. (1996), “An evaluation of incremental fit indices: A clarification of mathematical and empirical properties", In G.A. Marcoulides and R.E. 
Schumacker, (Eds.), Advanced Structural Equation Modeling: Issues and Techniques, Erlbaum, Mahwah, NJ.

Mastenbroek, N.J.J.M., Jaarsma, A.D.C., Scherpbier, A.J.J.A., van Beukelen, P., and Demerouti, E. (2014), "The role of personal resources in explaining well-being and performance: A study among young veterinary professionals", European Journal of Work and Organizational Psychology, Vol. 23, pp. 190-202.

McCarthy, J.M., Trougakos, J.P., and Cheng, B.H. (2016), "Are anxious workers less productive workers? It depends on the quality of social exchange", Journal of Applied Psychology, Vol. 101, pp. 279-291.

Mintzberg, H. (1973), The Nature of Managerial Work, Harper and Row, New York.

Motowidlo, S.J. (2000), "Some basic issues related to contextual performance and organizational citizenship behavior in human resources management", Human Resources Management Review, Vol. 10, pp. 115-126.

Motowidlo, S.J. (2003), "Job performance," in W.C. Borman, D.R. Ilgen, and R.J. Klimoski (Eds.), Industrial and Organizational Psychology: Handbook of Psychology, Vol. 12, Wiley, Hoboken, NJ, pp. 39-53.

Motowidlo, S.J., Borman, W.C., and Schmit, M.J. (1997), "A theory of individual differences in task and contextual performance", Human Performance, Vol. 10, pp. 71-83.

Naseer, S., Raja, U., Syed, F., Donia, M.B.L., and Darr, W. (2016), "Perils of being close to a bad leader in a bad environment: Exploring the combined effects of despotic leadership, leader member exchange, and perceived organizational politics on behaviors", The Leadership Quarterly, Vol. 27, pp. 14-33.

Ng, T.W.H. and Feldman, D.C. (2009), "How broadly does education contribute to job performance?", Personnel Psychology, Vol. 62, pp. 89-134.

Ng, T.W.H. and Feldman, D.C. (2012), "Employee voice behavior: A meta-analytic test of the conservation of resources framework", Journal of Organizational Behavior, Vol. 33, 216234.

Parker, S.K. (1998), "Enhancing role breadth self-efficacy: The roles of job enrichment and other organizational interventions", Journal of Applied Psychology, Vol. 83, pp. 835-852.

Podsakoff, P.M., Ahearne, M., and MacKenzie, S.B. (1997), "Organizational citizenship behavior and the quantity and quality of work group performance", Journal of Applied Psychology, Vol. 82, pp. 262-270.

Quinn, R.W., Spreitzer, G.M., and Lam, C.F. (2012), "Building a sustainable model of human energy in organizations: Exploring the critical role of resources", Academy of Management Annals, Vol. 6, pp. 337-396.

Raja, U., Johns, G., and Bilgrami, S. (2011), "Negative consequences of felt violations: The deeper the relationship, the stronger the reaction", Applied Psychology: An International Review, Vol. 60, 397-420.

Ryan, R.M. and Deci, E.L. (2000), "Self-determination theory and the facilitation of intrinsic motivation, social development, and well-being", American Psychologist, Vol. 55, pp. 68-78.

Schmitz, C. and Ganesan, S. (2014), "Managing customer and organizational complexity in sales organizations", Journal of Marketing, Vol. 78, pp. 59-77.

Scott, S. G. and Bruce, R. A. (1994), "Determinants of innovative behavior: A path model of individual innovation in the workplace", Academy of Management Journal, Vol. 37, 580607. 
Seibert, S., Kraimer, M.L., and Liden, R. (2001), "A social capital theory of career success", Academy of Management Journal, Vol. 44, pp. 219-237.

Siu, O.L., Lu, C.Q., and Spector, P.E. (2013), "Direct and indirect relationship between social stressors and job performance in Greater China: The role of strain and social support", European Journal of Work and Organizational Psychology, Vol. 22, pp. 520-531.

Smith, A. and Williams, K.D. (2004), "R U there? Effects of ostracism by cell phone messages", Group Dynamics: Theory, Research, and Practice, Vol. 8, pp. 291-301.

Spector, P.E. (2006), "Method variance in organizational research: Truth or urban legend?", Organizational Research Methods, Vol. 9, pp. 221-232.

Stock, R.M. (2015), "Is boreout a threat to frontline employees' innovative work behavior?", Journal of Product Innovation Management, Vol. 32, pp. 574-592.

Stroud, L.R., Tanofsky-Kraff, M., Wilfley, D.E., and Salovey, P. (2000), “The Yale Interpersonal Stressor (YIPS): Affective, physiological, and behavioral responses to a novel interpersonal rejection paradigm", Annals of Behavioral Medicine, Vol. 22, pp. 204-213.

Thomas, C.H. and Lankau, M.J. (2009), "Preventing burnout: the effects of LMX and mentoring on socialization, role stress, and burnout", Human Resource Management, Vol. 48, 417-432.

Twenge, J.M., Baumeister, R.F., DeWall, C.N., Ciarocco, N.J., and Bartels, J.M. (2007), "Social exclusion decreases prosocial behavior", Journal of Personality and Social Psychology, Vol. 92, pp. 56-66.

Twenge, J.M., Baumeister, R.F., Tice, D.M., and Stucke, T.S. (2001), "If you can't join them, beat them: Effects of social exclusion on aggressive behavior", Journal of Personality and Social Psychology, Vol. 81, pp. 1058-1069.

van Seggelen-Damen, I. and van Dam, K. (2016), "Self-reflection as a mediator between selfefficacy and well-being", Journal of Managerial Psychology, Vol. 31, pp. 18-33.

Vancouver, J.B., Thompson, C.M., Tischner, E.C., and Putka, D.J. (2002), "Two studies examining the negative effect of self-efficacy on performance", Journal of Applied Psychology, Vol. 87, pp. 506-516.

Vardi, Y., and Weitz, E. (2004), Misbehavior in Organizations: Theory, Research, and Management, Lawrence Erlbaum Associates, Mahwah, NJ.

Watt, J.D. and Hargis, M.B. (2010), "Boredom proneness: Its relationship with subjective underemployment, perceived organizational support, and job performance", Journal of Business and Psychology, Vol. 25, pp. 163-174.

Williams, K.D. (2001), Ostracism: The Power of Silence, Guilford Press, New York.

Williams, K.D. (2007), “Ostracism”, Annual Review of Psychology, Vol. 58, pp. 425-452.

Williams, L.J. and Anderson, S. E. (1991), "Job satisfaction and organizational commitment as predictors of organizational citizenship and in-role behavior", Journal of Management, Vol. 17 , pp. 601-617.

Wood, R. and Bandura, A. (1989). Impact of conceptions of ability on self-regulatory mechanisms and complex decision making", Journal of Personality and Social Psychology, Vol. 56, pp. 407-415.

Wu, L., Yim, F. H.-K., Kwan, H. K., and Zhang, X. (2012), "Coping with workplace ostracism: The roles of ingratiation and political skill in employee psychological distress", Journal of Management Studies, Vol. 49, pp. 178-199.

Zadro, L., Williams, K. D., and Richardson, R. (2004), "How low can you go? Ostracism by a computer is sufficient to lower self-reported levels of belonging, control, self-esteem, and meaningful existence", Journal of Experimental Social Psychology, Vol. 40, pp. 560-567. 
Zadro, L., Williams, K.D., and Richardson, R. (2005), "Riding the 'O' train: Comparing the effects of ostracism and verbal dispute on targets and sources", Group Processes and Intergroup Relations, Vol. 8, pp. 125-143.

Zimmerman, R.D. and Darnold, T.C. (2009), "The impact of job performance on employee turnover intentions and the voluntary turnover process: A meta-analysis and path model”, Personnel Review, Vol. 38, pp. 142-158. 
Figure 1: Conceptual model

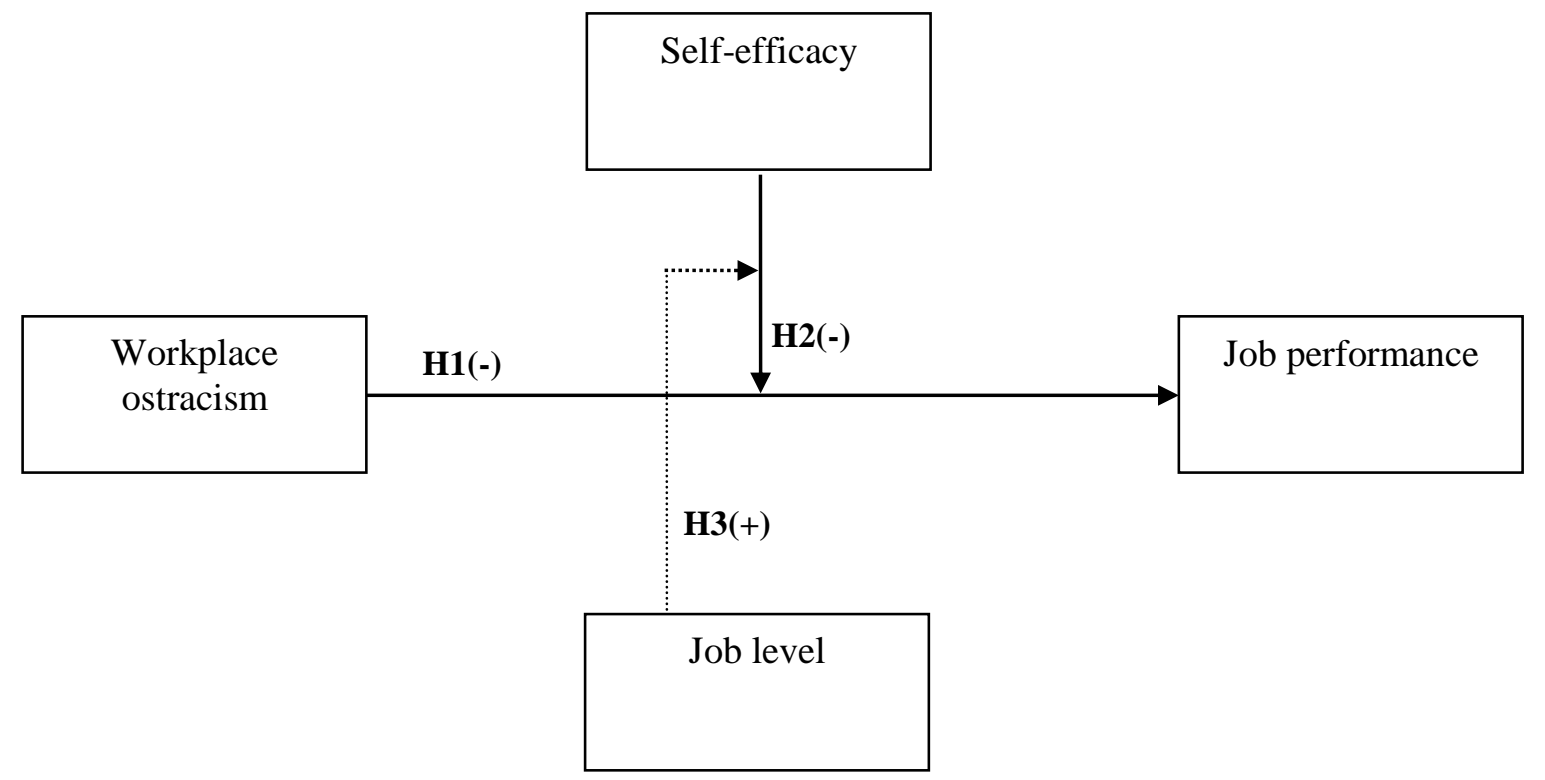


Figure 2: Moderating effect of self-efficacy on the relationship between workplace ostracism and job performance

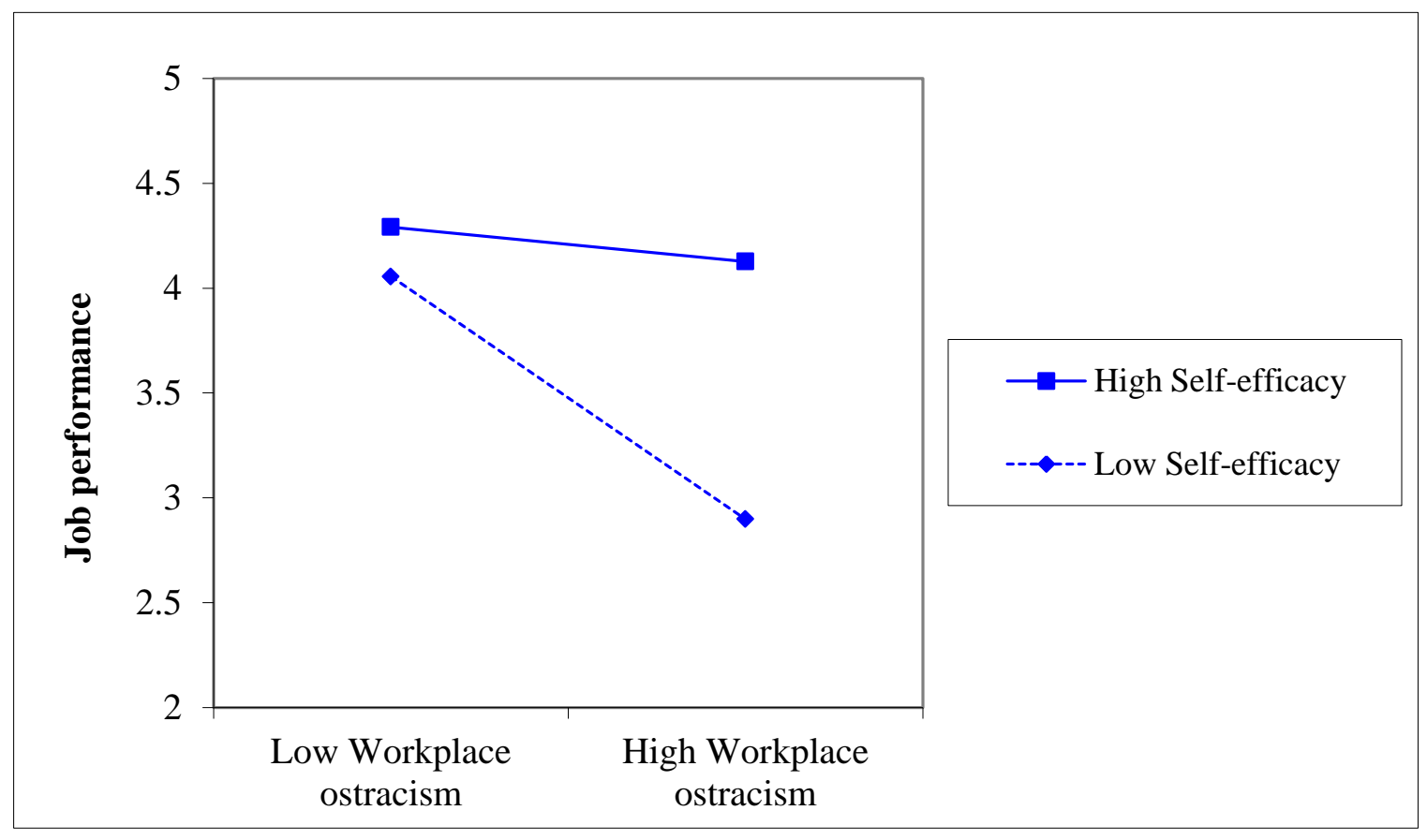


Figure 3: Three-way interaction effect

A: Self-efficacy on workplace ostracism-job performance relationship when job level is high

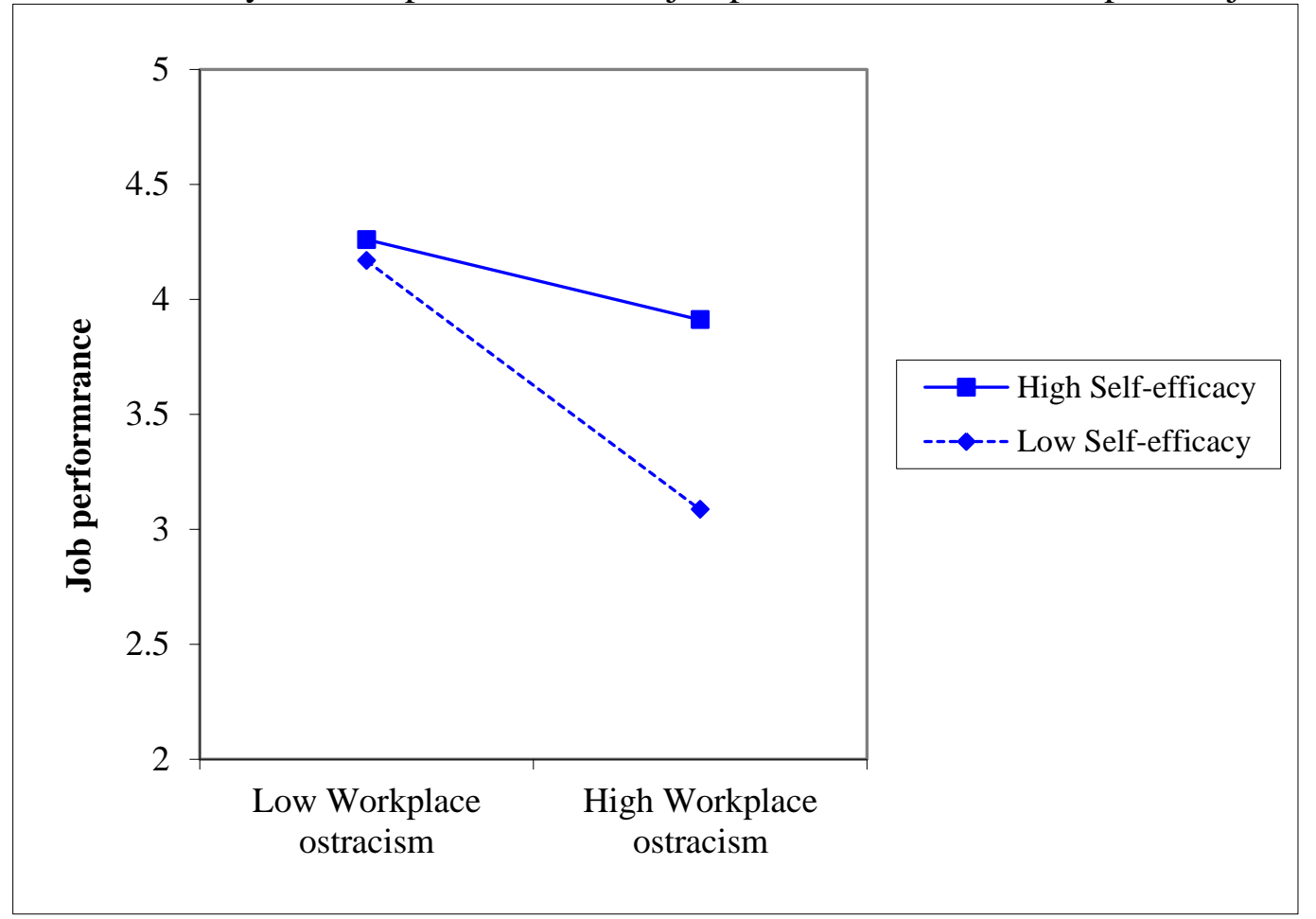

B: Self-efficacy on workplace ostracism-job performance relationship when job level is low

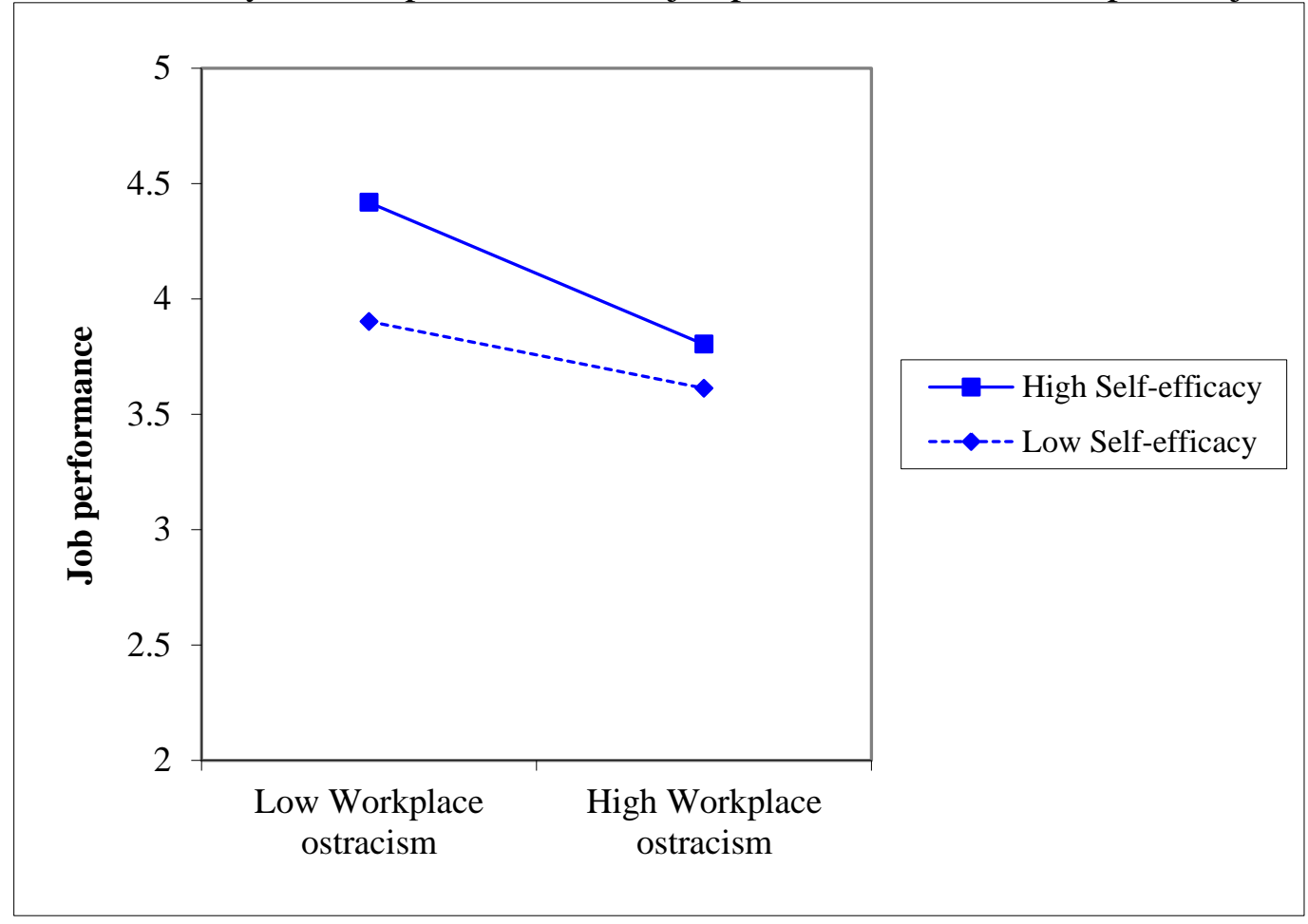


Table 1: Constructs and measurement items

\begin{tabular}{|c|c|c|}
\hline & $\begin{array}{l}\text { Factor } \\
\text { Loading }\end{array}$ & t-Value \\
\hline \multicolumn{3}{|l|}{ Job performance } \\
\hline This employee adequately completes assigned duties. ${ }^{a}$ & .786 & -- \\
\hline This employee fulfills responsibilities specified in his/her job description. & 797 & 21.358 \\
\hline This employee performs tasks that are expected of him/her. & .815 & 15.807 \\
\hline This employee meets formal performance requirements of the job. & .815 & 13.536 \\
\hline $\begin{array}{l}\text { This employee engages in activities that will directly affect his/her performance } \\
\text { evaluation. }\end{array}$ & .733 & 11.944 \\
\hline $\begin{array}{l}\text { This employee neglects aspects of the job he/she is obligated to perform (reverse } \\
\text { coded). }\end{array}$ & .853 & 14.169 \\
\hline This employee fails to perform essential duties (reverse coded). & .817 & 13.47 \\
\hline \multicolumn{3}{|l|}{ Workplace ostracism } \\
\hline Others ignore me at work. & 413 & 5.935 \\
\hline Others leave the area when I enter. & .675 & 9.028 \\
\hline My greetings go unanswered at work. & 639 & 8.645 \\
\hline I involuntarily sit alone in a crowded lunchroom at work. & .635 & 8.599 \\
\hline Others avoid me at work. & .609 & 8.313 \\
\hline I have noticed that others do not look at me at work. & 686 & 9.144 \\
\hline Others at work shut me out of the conversation. & .684 & 9.122 \\
\hline Others refuse to talk to me at work. & 709 & 9.379 \\
\hline Others at work treat me as if I weren’t there. & .737 & 9.646 \\
\hline $\begin{array}{l}\text { Others at work do not invite me or ask me if I want anything when they go out on } \\
\text { a break. }\end{array}$ & .629 & -- \\
\hline \multicolumn{3}{|l|}{ Self-efficacy } \\
\hline I feel confident analyzing a long-term problem to find a solution. ${ }^{\mathrm{a}}$ & 673 & -- \\
\hline I feel confident in representing my work area in meetings with management. & .821 & 9.955 \\
\hline I feel confident contributing to discussions about the organization's strategy. & 642 & 8.56 \\
\hline I feel confident helping to set targets/goals in my work area. & .553 & 7.494 \\
\hline
\end{tabular}

${ }^{a}$ Initial loading was fixed to 1 , to set the scale of the construct. 
Table 2: Correlation table and descriptive statistics

\begin{tabular}{|c|c|c|c|c|c|c|c|c|}
\hline & Mean & SD & 1 & 2 & 3 & 4 & 5 & 6 \\
\hline 1. Job performance & 4.161 & .678 & & & & & & \\
\hline 2. Workplace ostracism & 1.827 & .777 & $-.384^{* *}$ & & & & & \\
\hline 3. Self-efficacy & 4.945 & .589 & $.286^{* *}$ & -.002 & & & & \\
\hline 4. Job level ( $1=$ managerial position $)$ & .461 & .499 & .098 & -.083 & $.269^{* *}$ & & & \\
\hline 5. Gender $(1=$ female $)$ & .248 & .433 & .019 & .008 & $-.320^{* *}$ & -.063 & & \\
\hline 6. Age & 1.167 & .394 & .076 & -.059 & .098 & .122 & $-.175^{* *}$ & \\
\hline 7. Education & 2.733 & .679 & -.023 & .033 & $-.136^{*}$ & .044 & $.333^{* *}$ & -.007 \\
\hline
\end{tabular}

Notes: $\mathrm{N}=258$.

$* * p<.01 ; * p<.05$. 
Table 3: Regression results (dependent variable: job performance)

\begin{tabular}{|c|c|c|c|c|}
\hline & Model 1 & Model 2 & Model 3 & Model 4 \\
\hline Gender ( 1 = female $)$ & .072 & $.215^{*}$ & $.201 *$ & $.166^{+}$ \\
\hline Age & .144 & .082 & .076 & .057 \\
\hline Education & -.038 & -.011 & -.001 & .003 \\
\hline $\mathrm{H}_{1}$ : Workplace ostracism & & $-.334 * * *$ & $-.330 * * *$ & $-.374 * * *$ \\
\hline Self-efficacy & & $.378 * * *$ & $.366 * * *$ & $.344 * * *$ \\
\hline Job level (1 = managerial position) & & -.025 & -.040 & -.078 \\
\hline $\mathrm{H}_{2}:$ Workplace ostracism $\times$ self-efficacy & & & $.248 * * *$ & .111 \\
\hline Workplace ostracism $\times$ job level & & & & -.169 \\
\hline Self-efficacy $\times$ job level & & & & .089 \\
\hline $\begin{array}{l}\mathrm{H}_{3}: \text { Workplace ostracism } \times \text { self-efficacy } \\
\quad \times \text { job level }\end{array}$ & & & & $.576^{* * * *}$ \\
\hline $\begin{array}{r}\mathrm{R}^{2} \\
\mathrm{R}^{2} \text { change }\end{array}$ & .008 & $\begin{array}{c}.245 \\
.237 * * *\end{array}$ & $\begin{array}{c}.287 \\
.042 * * *\end{array}$ & $\begin{array}{c}318 \\
.031^{*}\end{array}$ \\
\hline
\end{tabular}

Notes: $\mathrm{N}=258$.

${ }^{* * *} p<.001 ;{ }^{* *} p<.01 ;{ }^{*} p<.05 ;{ }^{+} p<.10$ (two-tailed tests). 